Engineering Sustainability

Volume 170 Issue ES5

Climate change impacts on railway

structures: bridge scour

Dikanski, Hagen-Zanker, Imam and Avery
Proceedings of the Institution of Civil Engineers

Engineering Sustainability 170 October 2017 Issue ES5

Pages 237-248 http://dx.doi.org/10.1680/jensu.15.00021

Paper 1500021

Received 01/04/2015 Accepted 10/05/2016

Published online 06/06/2016

Keywords: bridges/floods \& floodworks/weather

\title{
Climate change impacts on railway structures: bridge scour
}

Hristo Dikanski MEng

Research Engineer (Climate Change Adaptation), University of Surrey, Guildford, UK; Network Rail, Milton Keynes, UK (corresponding author: hristo.dikanski@networkrail.co.uk)

Alex Hagen-Zanker PhD

Lecturer, University of Surrey, Guildford, UK

\section{Boulent Imam PhD}

Senior Lecturer, University of Surrey, Guildford, UK

Kate Avery PhD

Programme Manager, Network Rail, Cardiff, UK

Weather-related disruption is a pressing issue for transport infrastructure in the UK, which is expected to aggravate due to climate change. Infrastructure managers, such as Network Rail, need to adapt to these changes, tackling the challenges brought about by wide-ranging uncertainties from various sources. This paper explores the relationship between climate change and bridge scour, identifying barriers to sustainable adaptation. Scour is the removal of riverbed material at bridge foundations due to hydraulic action and is the foremost cause of bridge failure in the UK and worldwide. A model is developed that simulates the causal chain from climate change to scour risk. This is applied to four case study bridges in Wales and the south-west of England, quantifying the effects of climate change and tracing key uncertainties in the process. Results show that the current scour risk models in Network Rail may be insensitive to increases in risk due to climate change. One way to tackle this may be to introduce models to assess absolute risk; current scour risk models are used only for the prioritisation of vulnerable sites.

\section{Notation}

width of pier or abutment

$d_{0} \quad$ contraction scour

$d_{\mathrm{f}} \quad$ foundation depth

$d_{\mathrm{s}} \quad$ local scour

$d_{\mathrm{t}} \quad$ total scour

E energy head

$E_{\mathrm{A}} \quad$ energy just upstream of the bridge

$E_{\mathrm{B}} \quad$ energy at the bridge

$F_{\text {angle }} \quad$ factor for angle of attack

$F_{\text {debris }} \quad$ debris factor

$F_{\text {depth }} \quad$ flow depth factor

FPR final priority rating

Fr Froude number

$\mathrm{Fr}_{1} \quad$ Froude number directly upstream of the pier

$F_{\text {shape }} \quad$ shape factor

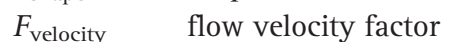

g acceleration due to gravity

$K_{1}, K_{2}, K_{3}$ factors in the HEC-18 local scour equation

$n \quad$ Manning's coefficient

$P \quad$ flow perimeter

$p \quad$ pressure

PPR preliminary priority rating

Q discharge

$\mathrm{RP} \quad$ return period

RP20 20-year return period

RP50 50-year return period

RP200 200-year return period

$S \quad$ average channel slope

$S_{\mathrm{e}} \quad$ hydraulic grade line

$\begin{array}{ll}S_{\mathrm{F}} & \text { safety factor } \\ V & \text { flow velocity } \\ y_{1} & \text { flow depth } \\ Z & \text { elevation } \\ \rho & \text { density }\end{array}$

\section{Introduction}

Severe weather often causes disruption to transport networks in the UK and introduces significant challenges for infrastructure asset managers. Landslides, flooding and strong winds are some of the numerous weather-related hazards, affecting transport infrastructure. This paper concentrates on railway infrastructure in the UK.

The railway has been affected heavily by weather in the recent past. Network failures such as the collapse of the Dawlish sea wall and extensive flooding at Hinksey have revealed weaknesses in the UK's resilience to extreme weather events (Network Rail, 2014).

During the eight years between 2006/2007 and 2013/2014, Network Rail paid an average of over $£ 50$ million each year for weather-related disruption in compensation for network disruption to train and freight operators (Network Rail, 2014).

Such levels of performance costs and the broader socio-economic impacts of network disruption necessitate further increase in the resilience of transport infrastructure to weather and the impacts of climate change. In addition, interdependencies between transport and other infrastructure systems call for a greater understanding of the wider impacts of severe weather. Bearing in mind that such impacts are likely to be affected by global climate change, increasing the knowledge of the complex relationships between 
Climate change impacts on railway

structures: bridge scour

Dikanski, Hagen-Zanker, Imam and Avery weather and asset performance is a crucial aspect of sustainable adaptation.

\subsection{Climate change and transport infrastructure}

In their fifth assessment report, the Intergovernmental Panel on Climate Change (IPCC) confirmed that 'warming of the climate system is unequivocal' (IPCC, 2013: p. 4); one consequence of this warming is that many severe weather events are likely to increase in frequency and intensity. In addition, it has been found that hydrological systems across the globe are being affected by processes, such as changing precipitation patterns and melting ice sheets.

The UK Climate Projections 2009 (UKCP09) have been developed in an attempt to quantify and map the effects of global climate change on UK climate. On the average, the UK is expected to experience hotter, drier summers and wetter, warmer winters (Jenkins et al., 2009).

The projections are associated with various uncertainties, for which the three main sources are the natural variability of the climate, incomplete understanding of the climate system and future greenhouse gas emissions. The modelling uncertainty is increased by the fact that the UKCP09 are a tool that downscales global climate models supporting the IPCC's Fourth Assessment Report (IPCC, 2007); stronger evidence presented in the Fifth Assessment Report Report (IPCC, 2014) is not reflected in the UKCP09.

The first UK Climate Change Risk Assessment, published in 2012, identified four major climate change risks to railway infrastructure (Thornes et al., 2012)

- flooding

- landslides

rail buckling

- bridge scour.

This research focused on the risk of bridge scour.

\subsection{Bridge scour}

Scour is the removal of riverbed material at bridge foundations due to hydraulic action and is the foremost cause of bridge failure in the UK and worldwide. Van Leeuwen and Lamb (2014) summarised all flood- and scour-related failure incidents in railway bridges and culverts in the UK between 1846 and 2013, identifying a total of 138 failures. Seventeen of these failures occurred between 2003 and 2013, including the Feltham rail bridge collapse in 2009 and several bridge collapses during flooding in Cumbria earlier the same year. More recently, a number of bridges in Cumbria were damaged or washed away during the floods caused by Storm Desmond in November 2015 (Pitcher, 2015).

There are three main components of scour: general bed degradation; contraction scour, caused by the contraction of flow at the bridge opening; and local scour around a bridge pier or abutment. General scour tends to occur gradually over time and is not normally associated with a single flooding event.
Scour is affected by a variety of factors, including

- position and characteristics of structure

- flow conditions

- characteristics of riverbed, channel and floodplain.

These factors are subjected to high levels of uncertainty, brought about by changes in climate and limited data availability. In addition, infrastructure managers often work with simple, easy-touse scour models, whose accuracy may be low. The problem is exacerbated by the lack of comprehensive asset data, particularly in the case of older structures, where foundation conditions are often unknown and have to be assumed during scour assessments.

The potential effects of climate change on bridge scour in the USA and Europe were studied by Wright et al. (2012) and Nemry and Demirel (2012), respectively. These were national-level studies that explored aggregate risks and included assumptions about a linear relationship between increased rainfall and scour.

A more detailed assessment of future scour vulnerability of bridges in England was carried out by HR Wallingford (2014). It included explicit modelling of the link between flow depth and scour depth. The study did not assess the current risk to bridges due to limited access to bridge data; instead, it analysed the future increase in exposure to risk above the 'present day baseline'. Table 1 summarises HR Wallingford's results.

A number of large asset owners in the UK, including Network Rail, have adopted a nationwide $20 \%$ increase in peak flows for design purposes; this is based on research, commissioned by the Department for Food and Rural Affairs (Reynard et al., 2005). However, subsequent research has shown that applying such a rigid blanket climate change allowance may not be adequate, as it may not be conservative in some cases (Reynard et al., 2009).

The studies by Wright et al. (2012), Nemry and Demirel (2012) and HR Wallingford (2014) provided a good estimation of the potential high-level climate change impacts on bridge scour.

\begin{tabular}{lrrr}
\hline & $\begin{array}{c}\text { Proportion of bridges } \\
\text { per scour exposure } \\
\text { class: \% }\end{array}$ \\
\cline { 2 - 4 } Summary & Low & Medium & High \\
\hline 2020s medium emissions 50th percentile & 100 & 0 & 0 \\
2050s medium emissions 50th percentile & 99 & 1 & 0 \\
2080s low emissions 10th percentile & 100 & 0 & 0 \\
2080s high emissions 90th percentile & 69 & 26 & 5
\end{tabular}

Table 1. Proportion of major railway bridges over rivers per scour exposure class, as defined by HR Wallingford (2014) 
Engineering Sustainability

Volume 170 Issue ES5
Climate change impacts on railway

structures: bridge scour

Dikanski, Hagen-Zanker, Imam and Avery
However, no published research to date studied in detail the changes in risk at the individual asset level, which is needed for asset management evaluations and future investment decisions.

\subsection{Research aims and objectives}

The central aim of this paper is to improve the understanding of the link between climatic drivers and asset risk. In addition, technical barriers for sustainable adaptation that arise in current asset management practices need to be identified, to enable effective adaptation actions.

To achieve this aim, the causal chain of processes linking climate change to scour risk is identified and modelled for four case studies, identifying some major uncertainties in the analysis. Several reputable scour models are applied to the case study to estimate the relative importance of different flow characteristics in the assessment of scour risk.

\section{Methodology}

The current study focuses on bridge piers; however, similar principles can be applied for the assessment of bridge abutments.

Climate change affects weather patterns. Weather, particularly precipitation, affects river flow regimes and river discharge. These, in turn, influence flow depth and velocity, which has a direct impact on scour depths at bridge foundations. Scour depth relative to foundation depth directly affects risk. Each of these relationships has been modelled for a group of four selected case study bridges; the process is summarised in the flow chart in Figure 1.

Each stage in the chain of models introduces uncertainties from various sources, which propagate through the analysis. These uncertainties need to be identified and assessed to interpret reliably the results.

The processes linking climate change to scour risk are complex, and modelling them accurately requires a wealth of extensive data records. However, in practice, infrastructure operators are rarely in possession of comprehensive records. The complexity of the physical processes and the lack of comprehensive data introduce the need for metamodelling, simplifying parts of the analysis. Such metamodelling techniques are employed in this study, as detailed in this section.

\subsection{Climate and hydrological modelling}

Network Rail has adopted the UKCP09 high-emission scenario for its business adaptation purposes. This paper uses projections for the 2050s high emissions scenario.

To estimate the relationship between rainfall patterns and river discharge, the FD2020 methodology (Defra, 2009) is applied, which is described in a series of research papers (Kay et al., 2010; Prudhomme et al., 2010, 2013a, 2013b). It simulates the effect of a range of hypothetical climate change scenarios on catchments across the UK. Catchment responses to incremental changes in rainfall and temperature were recorded and summarised in response surfaces.

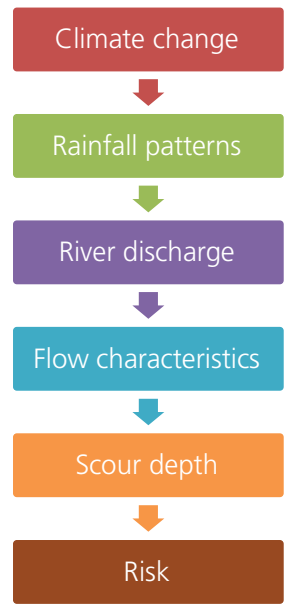

Figure 1. Steps involved in modelling the relationship between climate change and bridge scour risk

To apply the FD2020 method, 10000 realisations of the UKCP09 climate model were generated; the FD2020 method was applied individually to each of these, enabling the analysis of distribution and uncertainty of the climate data.

In the development of the FD2020 method, the Centre for Ecology and Hydrology team studied and incorporated a variety of uncertainties that arise within the hydrological analysis (Kay et al., 2014). Thus, the results include uncertainties within climate as well as hydrological modelling processes.

Originally, the FD2020 framework was designed to be applied for up to 50-year return period (RP) discharge events. Kay et al. (2010) studied the relationship between FD2020 results for changes in flow of various return periods for different types of catchments. This can be used to inform a simple extrapolation of FD2020 results to longer return periods.

Railway bridges are designed and assessed for a 200-year RP event. This means that the design river discharge has 1:200 (0.5\%) probability of exceedance in any given year. To obtain FD2020 results for the 200-year return period in this paper, an extrapolation uncertainty factor of 1.5 was applied to the estimated 50-year changes. This will both increase the expected mean increases and widen the uncertainty bands explored in the study. A more robust extrapolation method is not currently available.

\subsection{Hydraulic modelling}

A simplified geometry of the channel and floodplain is assumed, based on scour assessment data from Network Rail. The simplified plan of the river channel is shown in Figure 2. Crosssections $\mathrm{A}-\mathrm{A}$ and $\mathrm{B}-\mathrm{B}$ are shown in Figure 3.

Manning's equation is used to determine the depth and velocity of the steady-state uniform flow upstream of the structure. This is an 
Climate change impacts on railway

structures: bridge scour

Dikanski, Hagen-Zanker, Imam and Avery

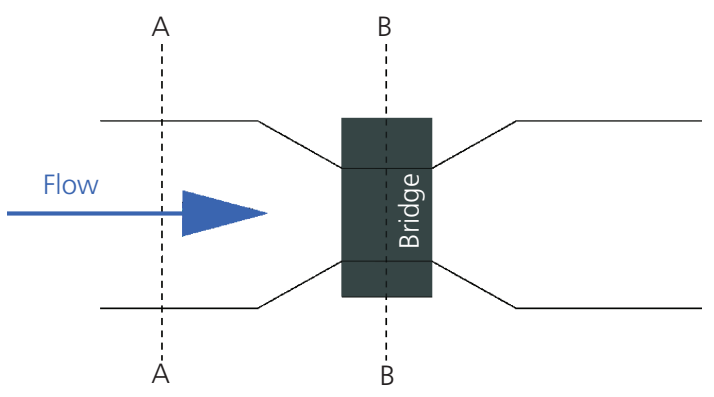

Figure 2. Simplified geometry: plan

empirical equation applicable to open channels; it links discharge $(Q)$, flow area $(A)$, flow perimeter $(P)$, slope of the hydraulic grade line $\left(S_{\mathrm{e}}\right)$ and Manning's coefficient $(n)$

1. $Q=\frac{A^{5 / 3}}{P^{2 / 3}}\left(\frac{S_{\mathrm{e}}^{1 / 2}}{n}\right)$

As the equation is applied to uniform steady-state flow, the slope of the hydraulic line $\left(S_{\mathrm{e}}\right)$ is assumed to be equal to the average channel slope $(S)$.

To determine flow depth and velocity at the bridge, where flow may not be uniform, Bernoulli's equation for conservation of energy is applied; see Equation 2. The energy is estimated at cross-sections $\mathrm{A}-\mathrm{A}$ and $\mathrm{B}-\mathrm{B}: E_{\mathrm{A}}$ is the energy just upstream of the bridge and $E_{\mathrm{B}}$ is the energy at the bridge. Friction losses between the two cross-sections are ignored.

2. $E_{\mathrm{A}}=\frac{p_{\mathrm{A}}}{\boldsymbol{g} \rho}+z_{\mathrm{A}}+\frac{V_{\mathrm{A}}^{2}}{2 \boldsymbol{g}}=\frac{p_{\mathrm{B}}}{\boldsymbol{g} \rho}+z_{\mathrm{B}}+\frac{V_{\mathrm{B}}^{2}}{2 \boldsymbol{g}}=E_{\mathrm{B}}$

where $E$ is the total energy head of a unit of fluid, $p_{\mathrm{a}} / \boldsymbol{g} \rho$ is the pressure head, $z$ is elevation head and $V_{\mathrm{A}}^{2} / 2 \boldsymbol{g}$ is the velocity head. Following Construction Industry Research and Information Association (Ciria) guidance, it is assumed that the maximum depth-averaged velocity for a given cross-section is $1 \cdot 15$ times larger than the average velocity for the section (Kirby et al., 2015).

This hydraulic assessment is associated with uncertainties due to data quality assumptions on the geometry and friction conditions as well as simplifications in the modelling equations. These are not quantified as part of this study and should be the subject of further investigation.

\subsection{Scour modelling}

Bridge scour assessments in Network Rail are carried out in two stages. Stage 1 is a preliminary assessment, based on the EX2502 scour method as detailed by Bettess (1993). This stage does not include any explicit consideration of flow conditions and therefore cannot detect any changes in risk due to climate change.

Stage 2 assessments are more robust than stage 1's and take into account a number of factors, including the characteristics of flow. The assessment for piers uses a combination of methods: to estimate contraction scour, the EX2502 method is used; the Ciria scour model is used for local scour analysis (Kirby et al., 2015).

Local scour at a bridge pier is estimated by using Equation 3, where $d_{\mathrm{s}}$ is the depth of local scour, $D$ is the pier width, $S_{\mathrm{F}}$ is a safety factor and the $F$ factors take into account different variables affecting the depth of scour: angle of attack $\left(F_{\text {angle }}\right)$, shape of the pier $\left(F_{\text {shape }}\right)$, depth $\left(F_{\text {depth }}\right)$, velocity $\left(F_{\text {velocity }}\right)$ and potential debris in the river $\left(F_{\text {debris }}\right)$.

3. $d_{\mathrm{s}}=D\left(F_{\text {angle }} F_{\text {shape }} F_{\text {depth }} F_{\text {velocity }} F_{\text {debris }}\right) S_{\mathrm{F}}$

$F_{\text {depth }}$ and $F_{\text {velocity }}$ are directly related to river flow, and this research focuses on them. Both factors range between 0 and 1 ; this means that there is a lower threshold, beyond which scour does not occur, and there is also an upper limit, beyond which scour does not increase with flow depth or velocity. This cap is linked to the velocity at the threshold of bed particle movement and the ratio between water depth and foundation width.

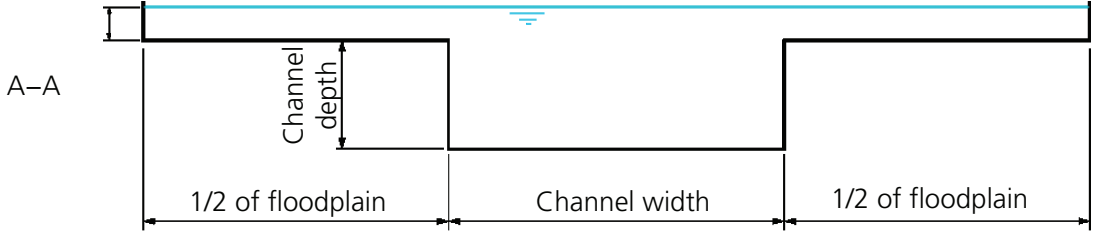

B-B

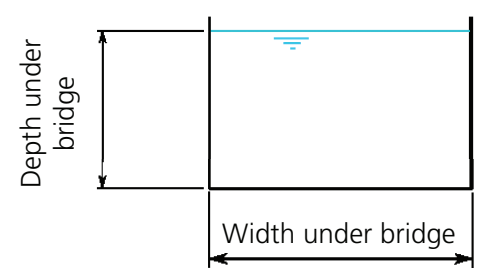

Figure 3. Simplified geometry: cross-sections 
Engineering Sustainability

Volume 170 Issue ES5
Climate change impacts on railway

structures: bridge scour

Dikanski, Hagen-Zanker, Imam and Avery
The premise of the capped effects of flow depth and velocity on local scour is summarised by Melville (2008); the theoretical maximum scour depth does not increase indefinitely with flow; however, the rate of scour can be significantly increased under increased flow depth and velocity.

To estimate variability associated with scour modelling, a number of alternative scour prediction models are explored - two for contraction scour and two for local scour.

The Ciria contraction scour model is based on the use of regime equations, predicting the long-term characteristics of natural channels under given flow conditions (Kirby et al., 2015). As individual floods tend to be only short-term events, the regime conditions are unlikely to be achieved during a single flood; thus, this model is conservative. The second contraction scour model is recommended by the Federal Highway Association (FHWA) in the USA, which takes into account the size of riverbed material and identifies two scour conditions. During live-bed scour, soil particles are in suspension upstream of the structure; as a consequence, some sediment is deposited in the scour hole during flood recession. During clear-water scour, velocities are insufficient for sediment transport upstream (Arneson et al., 2012).

These equations have been developed for cohesionless soils. The effects of cohesion in silts and clays on contraction scour can be very variable, and exploring these is outside the scope of this paper.

The two alternative local scour equations are detailed in the FHWA scour manual (Arneson et al., 2012). The hydraulic engineering circular (HEC) 18 method considers flow depth and velocity but does not account for their capped effect on scour depth. The method utilises Equation 4, where $d_{\mathrm{s}}$ is the depth of local scour, $y_{1}$ is the flow depth, $D$ is the pier width, $\operatorname{Fr}_{1}$ is the Froude number directly upstream of the pier and $K_{n}$ are factors accounting for pier shape $\left(K_{1}\right)$, angle of attack $\left(K_{2}\right)$ and bed condition $\left(K_{3}\right)$.

4. $\frac{d_{\mathrm{s}}}{y_{1}}=2 \cdot 0 K_{1} K_{2} K_{3}\left(\frac{D}{y_{1}}\right)^{0.65} \operatorname{Fr}_{1}^{0.43}$

The Florida Department of Transport (FDOT) local scour method is based on a more complete dimensional analysis than the HEC18 equation and includes considerations of bed material size and a more detailed consideration of the bridge pier flow field (Arneson et al., 2012). Similarly as the Ciria model, the FDOT method acknowledges the capped effect of flow velocity and depth on scour depth. The FDOT procedure explores several potential flow conditions and does not precipitate to a single equation; the detailed description is excluded from this paper for brevity.

A wide range of flow conditions is applied to each scour model to investigate the model's sensitivity to potential increases in flow. The results are matched to the results of the climatic and

\section{Combination}

number

Contraction scour

Local scour

1

2

3

4

4

EX2502

Ciria

FHWA

FHWA

Ciria

Ciria

HEC-18

FDOT

EX2502 (based on geometry,

Ciria

Table 2. Summary of local and contraction scour models used to assess total scour

hydrological assessment to estimate the potential effects of climate change on scour.

This analysis concentrates on scour which occurs during shortterm flood events. Long-term bed degradation is not explored; it is also normally excluded from Network Rail assessments. Five different combinations of local and contraction scour models are used in this paper to estimate total scour at each structure; these are summarised in Table 2.

Combination 5 in Table 3 reflects the current scour risk assessment procedure in Network Rail. Network Rail's contraction scour assessment does not explicitly account for flow conditions and uses the dimensions of the channel and floodplain to assess scour depth. Thus, potential increases in contraction scour due to climate change would not be detected.

\subsection{Risk modelling}

To assess the overall risk to the structure, Network Rail uses a 'priority rating' approach. Equation 5 shows how the preliminary priority rating of a structure is assessed (Bettess, 1993).

5. $\mathrm{PPR}=15+\ln \left(\frac{d_{\mathrm{t}}}{d_{\mathrm{f}}}\right)$

where PPR is the preliminary priority rating and $d_{\mathrm{f}}$ is the foundation depth. $d_{\mathrm{t}}$ is the predicted depth of scour that would

\begin{tabular}{lcc}
\hline Priority rating & Priority score & Priority category \\
\hline $17 \cdot 00-21 \cdot 00$ & Priority 1 & High \\
$16 \cdot 00-16.99$ & Priority 2 & High \\
$15 \cdot 00-15 \cdot 99$ & Priority 3 & Medium \\
$14.00-14.99$ & Priority 4 & Medium \\
$13 \cdot 00-13.99$ & Priority 5 & Low \\
$10.00-12.99$ & Priority 6 & Low
\end{tabular}

Table 3. Priority categories for scour management, based on Bettess (1993) 
occur following a 1:200-year flood event, and its estimation includes the use of conservative safety factors; it is not the actual scour depth at the bridge.

The PPR value is then adjusted to obtain the final priority rating (FPR), taking into account any existing scour protection and other conditions in the river channel and floodplain.

The FPR score is a dimensionless value that is used to compare the relative risks at different structures, so that they can be prioritised with respect to scour vulnerability and criticality. There are three priority categories, summarised in Table 3. Each of them is associated with different scour management actions.

Network Rail's bridge scour risk model is based on scour vulnerability, which is quantified using a ratio between foundation depth and predicted scour depth. The material consequences are not taken into account in the estimation of risk because any bridge failure is deemed to be unacceptable. However, the consequences of failure may differ for different bridges, based on the size of the structure and criticality of the route.

\subsection{Case studies}

The analysis was conducted for four case study bridges, situated in Wales and south-west of England. The case studies were selected to represent a wide range of conditions; some of the characteristics of the case studies are summarised in Table 4. The 200-year discharge values for each catchment are estimated using the Winfap-FEH software, part of the Flood Estimation Handbook (Reed et al., 2002); these estimates are based on extrapolation of historical records.

\section{Results and discussion}

\subsection{Climate and hydrological modelling}

The results of the climate and hydrological modelling are summarised in Figure 4, showing the mean increases in discharge for each return period.
Projections for the mean increase in RP20 and RP50 flows for a given site are very similar; the main difference between the results for the two return periods is an increase in the size of the relative uncertainty bands. The mean results for the 200-year flow are higher, and the respective uncertainty bands are wider - this is due to the extra uncertainty factor used to extrapolate the results to higher return period.

Sites 1 and 3 show similar flow responses, which are both lower than the potential flow increases at sites 2 and 4 . Site 2 shows the greatest potential increases in flow out of the four $-41 \cdot 1 \%$ expected increase in the 200 -year flow by the 2050 s, which may be as high as $95.1 \%$ for the 90th percentile of the climate and hydrological data. These differences result partly from variations in catchment characteristics, which lead to different catchment classifications, as explained in the FD2020 methodology (Kay et al., 2010). Variations in regional climate projections also have an effect on these results.

\subsection{Scour modelling}

Results from the contraction and local scour analysis are summarised in Figures 5 and 6, respectively, mapping scour depth variation against different discharge values for the selected sites. The studied range of flows is between the current 200-year discharge (RP200) for each catchment and 3 RP200, a 200\% increase. The results also incorporate findings from the climate and hydrological modelling, indicating the mean expected increase in discharge and the 90th percentile of the results.

The use of different scour models leads to substantially different predictions for both local and contraction scour depths.

Site 2 exhibits the greatest potential increases in the depth of contraction scour with climate change according to all of the explored scour models. For the mean expected increase in 200year flow, the EX2502 model predicts an increase in contraction scour depth of $1.9 \mathrm{~m}$, reaching a depth of $7.9 \mathrm{~m}$; this increase

\begin{tabular}{|c|c|c|c|c|}
\hline & \multicolumn{4}{|c|}{ Case study } \\
\hline & 1 & 2 & 3 & 4 \\
\hline Number of spans & 2 & 3 & 3 & 5 \\
\hline Material & $\begin{array}{l}\text { Steel deck, masonry } \\
\text { pier/abutments }\end{array}$ & Steel & Steel & Masonry arch \\
\hline Water flow & Slow & Slow & Slow & Moderate \\
\hline Foundation depth (pier): $m$ & 1.00 (assumed) & $1 \cdot 54$ & $2 \cdot 01$ & $1 \cdot 85$ \\
\hline Bed material & Gravel and stone & $\begin{array}{l}\text { Alluvial silt, sand, } \\
\text { gravel and bedrock }\end{array}$ & Silt, gravel, stone & Gravel \\
\hline Catchment & Moderate & Moderate & Moderate & Hilly \\
\hline 200-year discharge: $\mathrm{m}^{3} / \mathrm{s}$ & 53 & 168 & 475 & 473 \\
\hline
\end{tabular}

Table 4. Summary of characteristics of selected case studies 


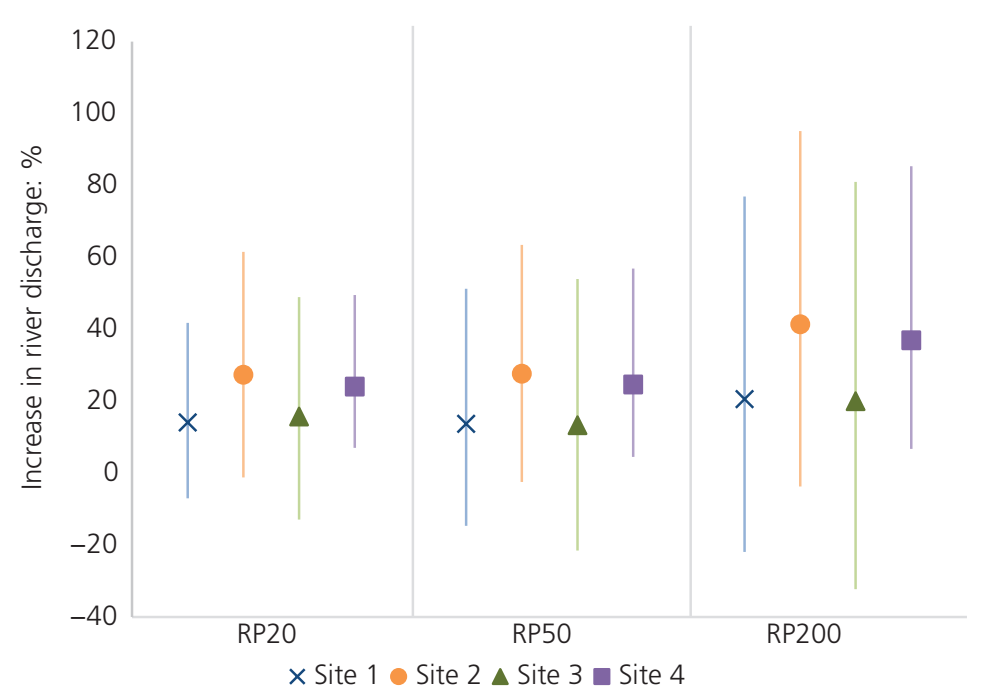

Figure 4. Projected increases in river discharge by the 2050s high emissions scenario for three return periods: 20, 50 and 200 years

may be up to $4.1 \mathrm{~m}$ for the 90th percentile of climate and hydrological data, resulting in $10 \cdot 1 \mathrm{~m}$ contraction scour depth. The expected increases in contraction scour depth according to Ciria and FHWA models are $1.9 \mathrm{~m}(4.5 \mathrm{~m}$ for the 90th percentile of data) and $1.0 \mathrm{~m}(2.3 \mathrm{~m}$ for the 90 th percentile of data), respectively. These differences in predictions for different sites occur partly due to geometric peculiarities at each site and partly due to differences in bed material properties. In particular, the riverbed at site 2 is predominantly sandy, which makes it more susceptible to contraction scour than other sites, where the bed material predominantly consists of gravel.

The selected contraction scour models generally assume long-term sustained flow conditions, rather than very short-term extreme conditions. This means that they are conservative when applied to very rare floods, which partly explains the relatively high predictions.

Site 1 shows a sudden increase in the FHWA contraction scour prediction between 30 and $35 \%$ increase in flow. The reason for this is a change from clear-water to live-bed conditions.

The climate change response in local scour predictions is not as pronounced as the estimates for contraction scour.

According to the Ciria model, the maximum local scour increase over the plausible climatic changes is $0.3 \mathrm{~m}-$ for site 4 . The FDOT is less sensitive for some sites - for example sites 3 and 4 - but more sensitive in the case of Site 2: $0.4 \mathrm{~m}$ local scour increase for the expected mean flow increase and up to $0.8 \mathrm{~m}$ for the largest plausible changes. These differences occur because the FDOT and Ciria equations recognise the capped effect flow depth and velocity have on local scour depth. Thus, where large flow depth and velocity are already observed, any increases due to climate change would not result in increased scour depth estimate. This also explains why, while predicting substantially different maximum scour depths, the FDOT and Ciria equations show similar scour depth increases with increase in river discharge.

The HEC-18 equation does not account for the capped effect of flow, and here increases in scour predictions are largest, reaching up to $1 \cdot 1 \mathrm{~m}$ over the plausible climatic changes for site 1 .

At two points on the graphs, results from the Ciria equation suggest that the depth of local scour decreases with an increase in flow - at $80 \%$ increase for site 1 and at $50 \%$ increase for site 3 . This is caused by the transition from subcritical to supercritical flow, where flow depth decreases and velocity increases. In these cases, velocity contribution to scour is at its maximum value; thus, the decrease in modelled flow depth results in a slight decrease in scour prediction. In reality, supercritical flow is often associated with the formation of a hydraulic jump where large energy dissipation can occur, leading to sediment erosion. However, this process is complex and is outside the scope of the current study.

\subsection{Risk modelling}

Modelled changes in the final priority rating (FPR) for the selected structures are plotted in Figure 7. As local scour increases are relatively low, the predicted increases in FPR are predominantly due to the increases in contraction scour depth. Hence, sites 2 and 4 show the greatest response in FPR. Site 2 shows a potential shift in risk classification: according to the Ciria methods, FPR may increase above 16 for the mean expected increase in river flows.

Site 1 shows a high FPR, despite relatively low predicted scour depths. Part of the reason for this is that the foundation depth is 

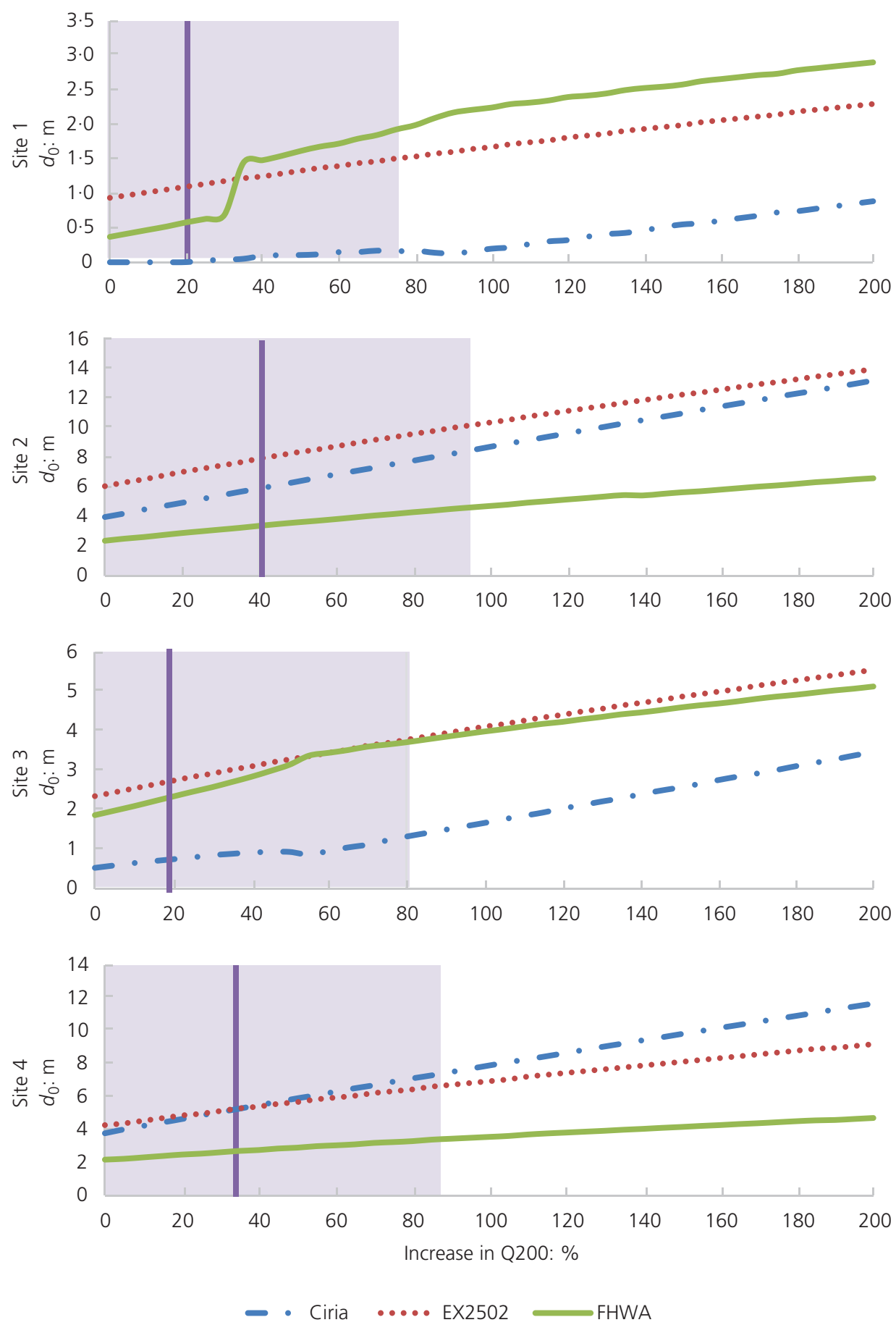

Figure 5. Contraction scour depth against increase in 200-year discharge for the four case studies. Projected mean increases in flow (vertical solid line) and the 90th percentile of results (shaded rectangle) are indicated

unknown and a safety factor is applied to the assessment. Thus, climate uncertainty has a relatively low effect on risk when compared with asset uncertainties, such as unknown foundation depth.
In practice, contraction scour assessment in Network Rail does not explicitly consider flow conditions; thus, the current method cannot detect major increases in risk due to climate change. This is illustrated by the results labelled 'NR method', which show a 

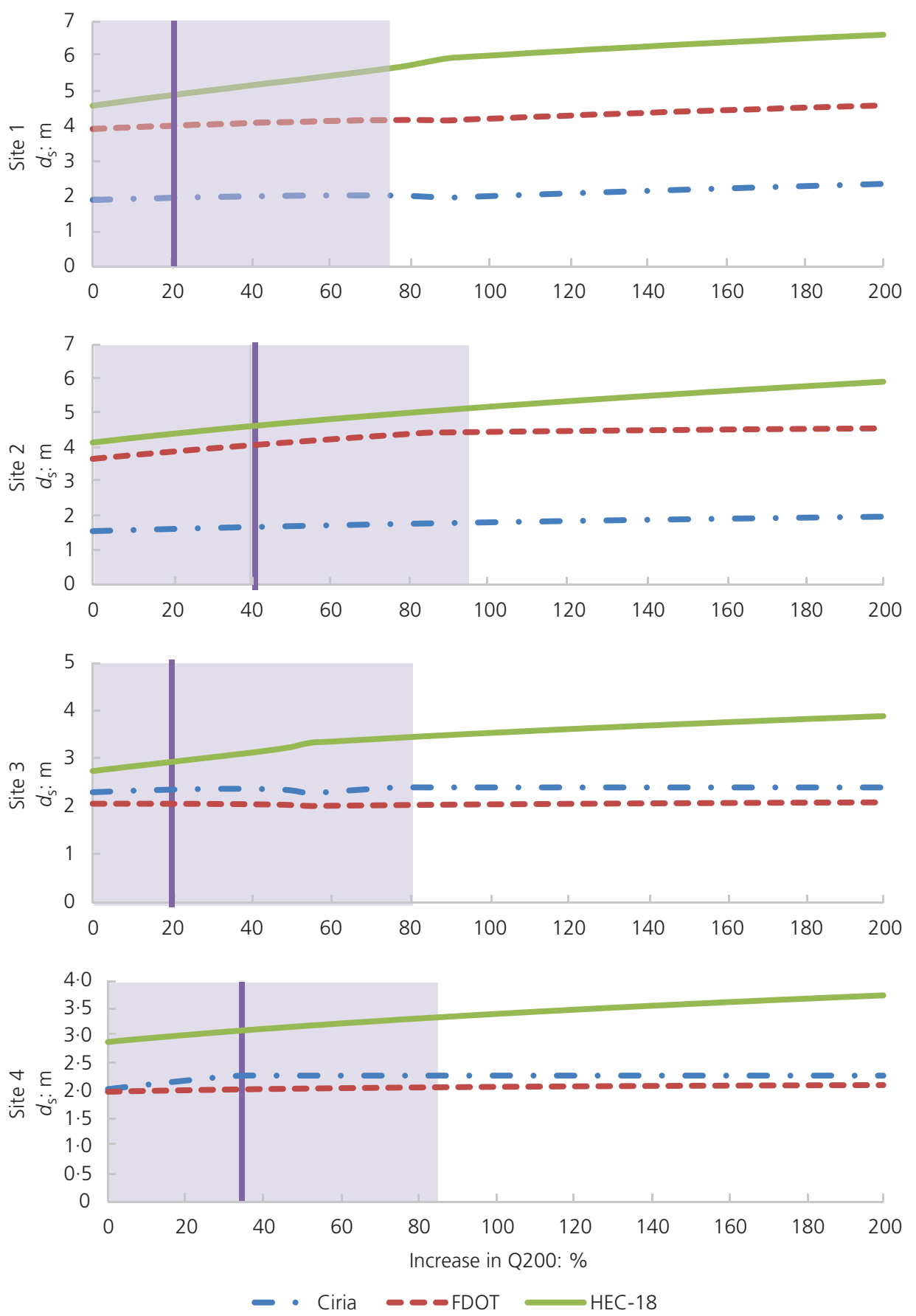

Figure 6. Local scour depth against increase in 200-year discharge for the four case studies. Projected mean increases in flow (vertical solid line) and the 90th percentile of results (shaded rectangle) are indicated

very low risk response even at the largest explored increases in river discharge. This highlights a potential weakness in current scour management procedures in Network Rail.

In addition, current assessments are based on the maximum scour depth which may result from a sustained 200-year flooding event.
While this maximum scour depth may not change substantially with increased flooding, particularly for local scour, the scour hole may develop more rapidly during intensive flow, increasing the actual risk to a bridge. This will not be detected by the current model, as it does not account for time effects in the development of scour. 

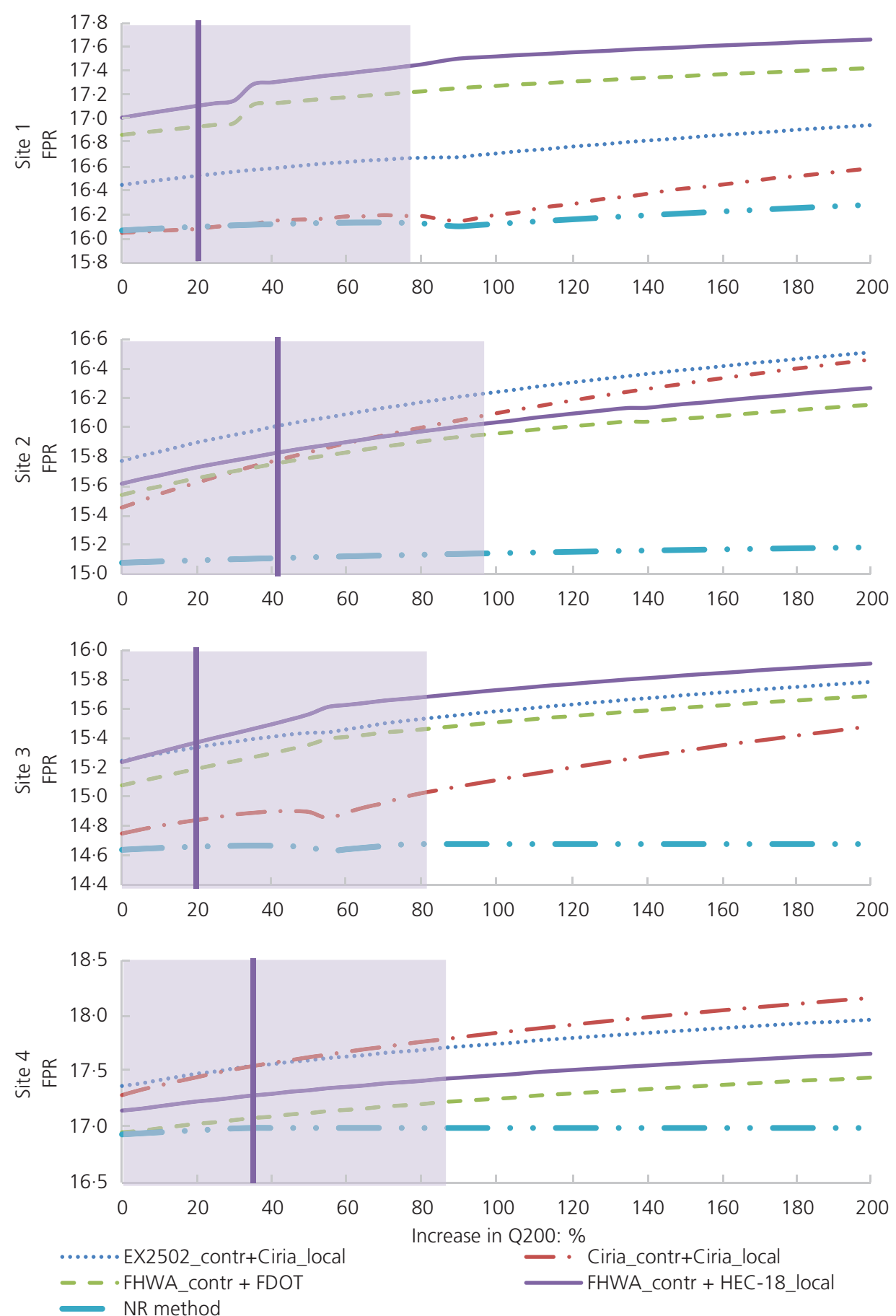

Figure 7. Final priority rating (FPR) against increase in the 200year discharge for the four case studies. Projected mean increases in flow (vertical solid line) and the 90th percentile of results (shaded rectangle) are indicated

The current risk model is based solely on a 200 -year event and is used for prioritisation of vulnerable sites. A potential improvement may be to estimate more accurately the absolute risk to a structure. This may be achieved by integrating over all plausible flow conditions that a bridge may be subjected to along with their probabilities of exceedance and the respective probabilities of failure. This would enable the adjustment of management procedures, such as assessment regimes, resulting in timely interventions. 
Engineering Sustainability

Volume 170 Issue ES5
Climate change impacts on railway

structures: bridge scour

Dikanski, Hagen-Zanker, Imam and Avery
This study focuses only on scour risk; other risks relating to hydraulic forces, including buoyancy, lateral pressure and the formation of a hydraulic jump, are not accounted for.

\section{Conclusions and future work}

This paper studies the risk response for a selection of case study bridges to a variety of climatic changes, according to several reputable scour assessment methods. The results show that the risk response varies for different sites and substantially depends on the method used for estimating scour depth.

The effect of increased water discharge on local scour is capped; thus, in many cases climate change may have a limited impact on the potential local scour depth during a 200-year river flow. Hence, the final risk rating is subject to a relatively low increase due to increased local scour. However, in high flow conditions, the scour hole can develop more rapidly; thus, the actual risk to a structure is increased. This will not be detected by Network Rail's scour risk model, as, while conservative, it does not account for time effects in the development of scour.

According to the studied models, the depth of contraction scour consistently increases with flow; thus, this scour type may be susceptible to climatic changes. Network Rail's contraction scour assessment does not explicitly account for flow conditions and therefore cannot detect any change in risk due to climate change. This, coupled with the limited effect of climate change on maximum scour depth, means that the company's scour risk model is unlikely to detect any major increase in scour risk in practice, highlighting a potential flaw in current practice.

Network Rail's scour risk model is currently based on the prioritisation of high-risk structures. Results suggest that while prioritisation may not change substantially according to the current assessment method in Network Rail, risk can be expected to increase across the board, as structures become subjected to more intensive and frequent flooding. One way to improve understanding of the evolution of risk with climate change is to introduce the estimation of absolute risk in assessments, in addition to relative risk necessary for prioritisation. This will enable Network Rail to detect the actual increase in risk and initiate a timely action to maintain the resilience of railway structures.

Uncertainties associated with climate change modelling are high. However, results suggest that in some cases, asset-specific uncertainties may be even more influential, particularly where foundation conditions are unknown. Reducing such asset uncertainties can improve the quality of scour assessments and improve Network Rail's resilience to current and future climatic conditions. Further investigation into the role of uncertainties in the analysis from various sources should be the focus of future research.

At the network level, several technical barriers for sustainable adaptation of scour management within Network Rail have been identified
- inability to rely on historical weather records to estimate trigger events and probabilities

n use of heuristic standards, whose future applicability is unknown

- complexity of causal chain from climate change to asset risk

variable quality of data used for asset condition assessment.

These barriers have been identified for the risk of bridge scour, but are likely to be relevant to the management of other asset types. In addition, similar issues will conceivably be echoed within other transport infrastructure operators.

Further efforts in this field are needed to develop an innovative asset management methodology that will thoroughly incorporate climate change considerations. To this end, research of potential adaptation options considering their whole-life value in the context of climate change would be valuable for asset managers. This would enable Network Rail to develop robust methodologies for sustainable adaptation of railway asset management.

\section{Acknowledgements}

This work forms part of a research project funded by the Engineering and Physical Sciences Research Council (EPSRC) and Network Rail. The work was completed as part of an engineering doctorate research programme with the University of Surrey.

The authors would like to thank the Structures RAM team within Network Rail's Western Route for their support throughout this research.

The authors would also like to thank the Centre for Ecology and Hydrology for their support.

\section{REFERENCES}

Arneson LA, Zevenbergen LW, Lagasse PF and Clopper PE (2012) Evaluating Scour at Bridges, 5th edn. Federal Highway Administration, US Department of Transportation Washington, DC, USA.

Bettess R (1993) Hydraulic Aspects of Bridges: Assessment of the Risk of Scour. HR Wallingford, Wallingford, UK.

Defra (Department for Environment, Food and Rural Affairs) (2009) Regionalised Impacts of Climate Change on Flood Flows - FD2020. Defra, London, UK. See http://randd.defra. gov.uk/Document.aspx?Document=FD2020_8852_FRP.pdf (accessed 02/06/2016).

HR Wallingford (2014) Indicators to Assess the Exposure of Critical Infrastructure in England to Current and Projected Climate Hazards. HR Wallingford, Wallingford, UK.

IPCC (Intergovernmental Panel on Climate Change) (2007) In Climate Change 2007: Synthesis Report. Contribution of Working Groups I, II and III to the Fourth Assessment Report of the Intergovernmental Panel on Climate Change (Core Writing Team, Pachauri RK and Reisinger A (eds)). IPCC, Geneva, Switzerland, 104 pp. 
Climate change impacts on railway

structures: bridge scour

Dikanski, Hagen-Zanker, Imam and Avery
IPCC (2013) Summary for policymakers. In Climate Change 2013: The Physical Science Basis. Contribution of Working Group I to the Fifth Assessment Report of the Intergovernmental Panel on Climate Change (Stocker TF, Qin D, Plattner GK et al. (eds)). Cambridge University Press, Cambridge, United Kingdom and New York, NY, USA.

IPCC (2014) Climate Change 2014: Synthesis Report. Contribution of Working Groups I, II and III to the Fifth Assessment Report of the Intergovernmental Panel on Climate Change (Core Writing Team, Pachauri RK and Meyer LA (eds)). IPCC, Geneva, Switzerland, 151 pp.

Jenkins GJ, Murphy JM, Sexton DMH et al. (2009) UK Climate Projections: Briefing Report. Met Office Hadley Centre, Exeter, UK.

Kay AL, Crooks S, Davies HN, Prudhomme C and Reynard NS (2010) Practicalities for Implementing Regionalised Allowances for Climate Change on Flood Flows. Department for Environment, Food and Rural Affairs, London, UK.

Kay AL, Crooks SM and Reynard NS (2014) Using response surfaces to estimate impacts of climate change on flood peaks: assessment of uncertainty. Hydrological Processes 28(20): 5273-5287, http://dx.doi.org/10.1002/hyp.10000.

Kirby AM, Roca M, Kitchen A, Escarameia M and Chesterton OL (2015) Manual on Scour at Bridges and Other Hydraulic Structures, 2nd edn. Ciria, London, UK.

Melville B (2008) The physics of local scour at bridge piers. In Fourth International Conference on Scour and Erosion 2008, Tokyo, Japan, pp. 28-40.

Nemry F and Demirel H (2012) Impacts of Climate Change on Transport: a Focus on Road and Rail Transport

Infrastructures. European Commission Joint Research Centre, Luxembourg, Luxembourg.

Network Rail (2014) Western Route: Weather Resilience and Climate Change Adaptation Plan. Network Rail, London, UK. Pitcher G (2015) Storm Desmond: bridges damaged. New Civil Engineer, 7 December. See http://www.newcivilengineer.com/ latest/storm-desmond-bridges-damaged/10000276.article (accessed 07/12/2015).

Prudhomme C, Wilby RL, Crooks S, Kay AL and Reynard NS (2010) Scenario-neutral approach to climate change impact studies: application to flood risk. Journal of Hydrology 390(3-4): 198-209, http://dx.doi.org/10.1016/j.jhydrol.2010. 06.043.

Prudhomme C, Crooks S, Kay AL and Reynard N (2013a) Climate change and river flooding: part 1 - classifying the sensitivity of British catchments. Climatic Change 119(3): 933-948, http://dx.doi.org/10.1007/s10584-013-0748-x.

Prudhomme C, Kay AL, Crooks S and Reynard N (2013b) Climate change and river flooding: part 2 - sensitivity characterisation for British catchments and example vulnerability assessments. Climatic Change 119(3): 949-964, http://dx.doi.org/10.1007/ s10584-013-0726-3.

Reed DW, Faulkner D, Robson A, Houghton-Carr H and Bayliss AC (2002) Flood Estimation Handbook. Centre for Ecology and Hydrology, Wallingford, UK.

Reynard NS, Crooks SM and Kay AL (2005) Impact of Climate Change on Flood Flows in River Catchments - Final Report. Environment Agency, Bristol, UK.

Reynard NS, Crooks S, Kay AL and Prudhomme C (2009) Regionalised Impacts of Climate Change on Flood Flows. Department for Environment, Food and Rural Affairs, London, UK.

Thornes J, Rennie M, Marsden H and Chapman L (2012) Climate Change Risk Assessment for the Transport Sector. Department for Food and Rural Affairs, London, UK.

Van Leeuwen Z and Lamb R (2014) Flood and Scour Related Failure Incidents at Railway Assets between 1846 and 2013. JBA Trust, Skipton, UK.

Wright L, Chinowsky P, Strzepek K et al. (2012) Estimated effects of climate change on flood vulnerability of U.S. bridges. Mitigation and Adaptation Strategies for Global Change 17(8): 939-955, http://dx.doi.org/10.1007/s11027-011-9354-2.

\section{HOW CAN YOU CONTRIBUTE?}

To discuss this paper, please email up to 500 words to the editor at journals@ice.org.uk. Your contribution will be forwarded to the author(s) for a reply and, if considered appropriate by the editorial board, it will be published as discussion in a future issue of the journal.

Proceedings journals rely entirely on contributions from the civil engineering profession (and allied disciplines). Information about how to submit your paper online is available at www.icevirtuallibrary.com/page/authors, where you will also find detailed author guidelines. 